\title{
CONTROLE DA CRIMINALIDADE NO ESPÍRITO SANTO: UMA PROPOSTA DE MODELO DE MENSURAÇÃO
}

\section{ARTIGO ORIGINAL}

FIGUEIREDO, Sabrina Oliveira de ${ }^{1}$

FIGUEIREDO, Sabrina Oliveira de. Controle da criminalidade no Espírito Santo: uma proposta de modelo de mensuração. Revista Científica Multidisciplinar Núcleo do Conhecimento. Ano 05, Ed. 03, Vol. 02, pp. 58-72. Março de 2020. ISSN: 24480959, Link de acesso: https://www.nucleodoconhecimento.com.br/lei/controle-dacriminalidade

\section{RESUMO}

O presente estudo tem como objetivo identificar os fatores determinantes do controle da criminalidade no estado do Espírito Santo. Para a análise dos níveis de criminalidade, consideraram-se os índices de homicídios dolosos. Em um primeiro momento, a pesquisa descreverá o cenário da segurança pública no Espírito Santo, demonstrando que, desde o ano de 2010, o estado tem observado a redução no número de homicídios, tendo alcançado, em 2019, a menor taxa de homicídios para cada grupo de 100 mil habitantes nos últimos 23 anos. Posteriormente, com base no aporte teórico, foi realizada uma descrição acerca do domínio do construto "controle da criminalidade" bem como o trabalho propõe uma apresentação visual do modelo de mensuração proposto, contendo, nele, o construto principal e as quatro dimensões ("fatores demográficos", "fatores socioeconômicos", "atividade policial" e "sistema de justiça criminal"). Em seguida, o artigo traz a proposta de master list, e, assim, contempla as possíveis variáveis das dimensões do modelo de mensuração. E, por fim, destaca-se a importância do desenvolvimento do estudo para o sistema de gestão

\footnotetext{
${ }^{1}$ Advogada, Mestre e Doutoranda em Administração.
} 
da segurança pública estadual e para o avanço de pesquisas acadêmicas na área da segurança pública.

Palavras-chave: Fatores determinantes, controle da criminalidade, homicídios dolosos, modelo de mensuração.

\section{INTRODUÇÃO}

Os índices de criminalidade letal, notadamente os registros de homicídios dolosos, configuram uma temática complexa e preocupante no país e são pautas constantes na opinião pública, além de objeto de estudo na academia e de reflexão para os operadores e gestores do sistema de segurança pública e justiça criminal nos estados da federação brasileira. No Espírito Santo, a expansão do desenvolvimento industrial registrado na década de 1970 (CALIMAN, 2012), embora tenha sido importante para o progresso econômico do estado, desencadeou problemas conjunturais no espaço urbano - ligados, principalmente, à moradia, saúde e ao desemprego - e causou um aumento significativo nos índices de criminalidade. Siqueira (2009) descreve que a alta concentração de migrantes, particularmente na Região Metropolitana da Grande Vitória (RMGV)[2], decorrente da desestruturação agrária e da procura por postos de trabalho na indústria em ascensão naquela década, promoveu mudanças demográficas e socioeconômicas no território capixaba[3].

O Poder Público, aliado às transformações da época, não se preocupou em elaborar e implementar políticas públicas eficientes que intervissem nos problemas sociais. Nesse contexto, percebeu-se que as questões urbanas foram agravadas, em especial, a violência, que se tornou um gargalo para a gestão governamental do Espírito Santo (IJSN, 2011). No âmbito da segurança pública, as estatísticas demonstraram um crescimento no número de homicídios dolosos[4] na RMGV: a taxa bruta de 95 homicídios no final da década de 1970 aumentou para 1245 homicídios no final dos anos 90 , o que representou uma elevação de cerca de $1210 \%$, segundo dados do Sistema de Informações sobre Mortalidade do Departamento de Informática do Sistema Único de Saúde (SIM/DATASUS) (MINISTÉRIO DA SAÚDE, 2019). Constatou-se, também, que em se tratando de taxa de homicídios para cada grupo de 
100.000 habitantes, em 1980, o Espírito Santo e a Grande Vitória registraram taxas semelhantes, com cerca de 15 homicídios por 100 mil./hab.

Já no final da década, em 1988, as taxas aumentaram para 30 homicídios por 100 mil./hab. (IJSN, 2011). Contudo, é preciso ressaltar que em 1988 houve a promulgação da Constituição Federal do Brasil, o que representou um processo de transição democrático no país. A partir desse marco, observou-se alguns esforços isolados, em determinados estados, no setor da segurança pública, época em que os elevados índices de criminalidade e violência exigiam transformação no sistema de gestão pública de segurança (MUNIZ; ZACCHI, 2004). De acordo com Soares (2006), a segurança pública passou a ser tratada como um problema de gestão e estrutura organizacional, o que demandava tratar a temática com foco na priorização de políticas públicas eficientes, no sentido de criar mecanismos de diagnóstico, planejamento e avaliação das medidas preventivas para o enfrentamento da criminalidade.

O Espírito Santo, inclusive, é citado como parte do conjunto de estados junto com São Paulo, Pernambuco, Paraíba e Minas Gerais. Nessas regiões, o poder público empregou instrumentos de gestão orientados para resultados na área da segurança pública, o que surtiu efeitos positivos no que tange ao controle dos índices de criminalidade letal (IPEA, 2019). Ao analisar brevemente os números brutos e as taxas de homicídios para cada grupo de 100 mil habitantes registrados nas últimas décadas no Espírito Santo, percebe-se que o quadro evolutivo histórico se mostra relevante em termos sociais para a gestão pública estadual e para a academia. O Gráfico 1, apresentado a seguir, permite verificar que em 2009 o estado atingiu o maior registro de homicídios da série histórica (2034 homicídios dolosos), o que significou uma taxa de 58,3 homicídios dolosos por 100 mil./hab. (Gráfico 2). A taxa de homicídios registrada no estado em 2009 representou mais do que o dobro da taxa média dos homicídios do Brasil naquele mesmo ano (27,2 homicídios por 100 mil/hab.) (IPEA, 2019). 
Gráfico 1 - Evolução do número de homicídios dolosos registrados no Espírito Santo (1997-2019)

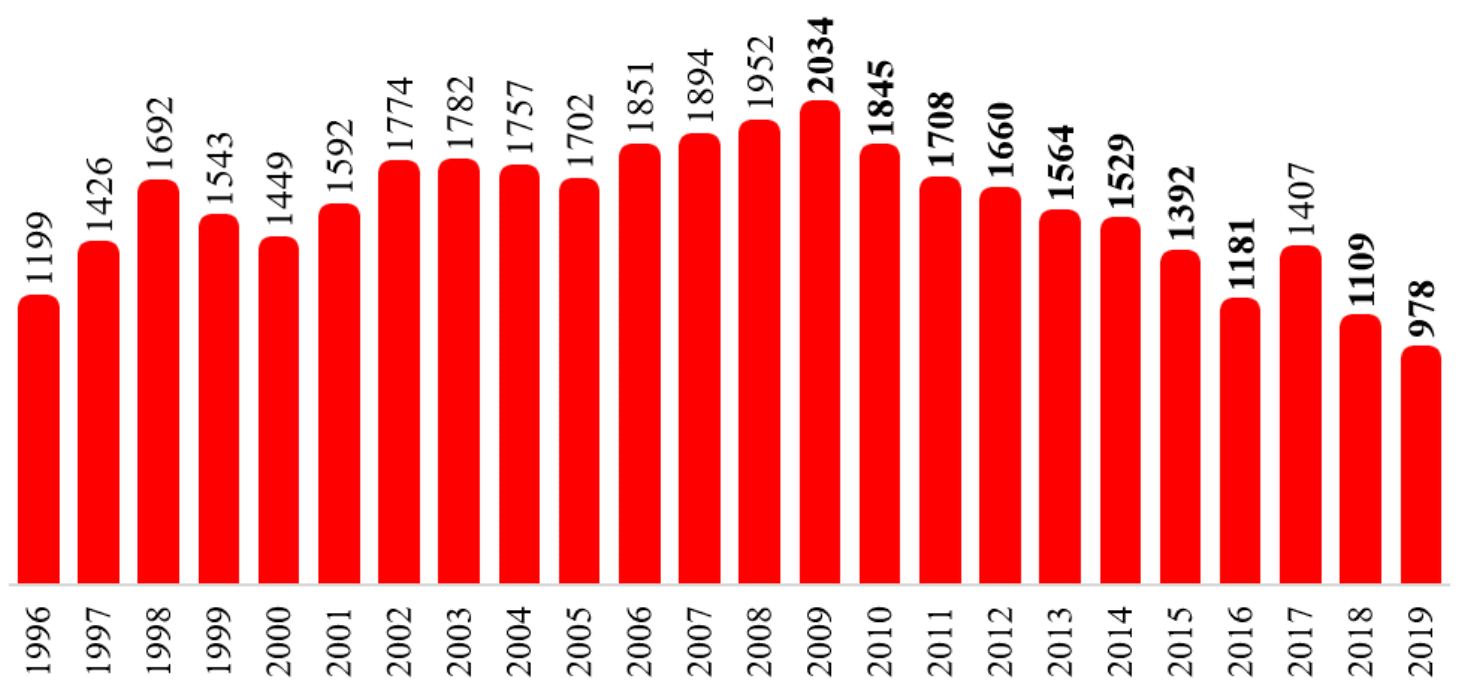

Fonte: Secretaria de Estado da Segurança Pública e Defesa Social (2020). Nota: Elaboração própria (2020).

Observa-se nos Gráficos 1 e 2 que a partir de 2010 o Espírito Santo tem apresentado uma involução no número de homicídios, tendo alcançado, em 2019, a menor taxa registrada nos últimos 23 anos (desde 1996). Por meio dos dois gráficos apresentados, também é possível perceber que o ano de 2017 representou um "ponto fora da curva". O aumento dos índices é justificado pela greve da Polícia Militar do estado, ocorrida em fevereiro/2017, quando 219 pessoas foram assassinadas no mês fatídico (IPEA, 2019). 
Gráfico 2 - Evolução da taxa de homicídios dolosos para cada grupo de 100 mil habitantes registrada no Espírito Santo (2007-2019)

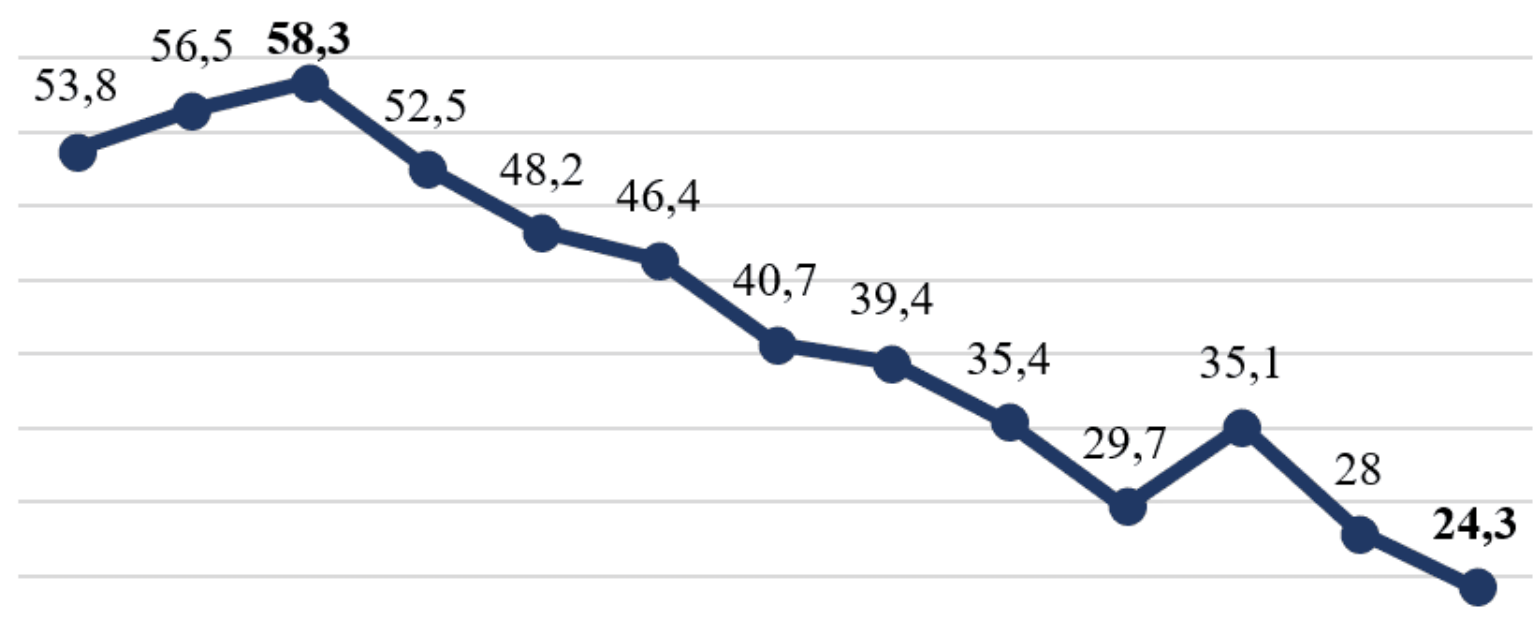

Fonte: Secretaria de Estado da Segurança Pública e Defesa Social (2019). Nota: Elaboração própria (2020).

Ao comparar os números brutos de homicídios registrados em 2009 e 2019, vislumbra-se uma redução de $51,9 \%$ dos homicídios no período analisado. Em se tratando de taxa de homicídios por $100 \mathrm{mil} / \mathrm{hab}$., observa-se que a diminuição dos índices, nesse mesmo período, atingiu a ordem de 58,3\%. Diante dessa breve exposição, que demonstra o inegável sucesso referente à queda dos registros de homicídios dolosos no território capixaba, o presente artigo traz o seguinte problema para a pesquisa: quais foram os fatores determinantes do controle da criminalidade no estado do Espírito Santo a partir do ano de 2010? Considera-se como parâmetro para compreensão do controle da criminalidade os registros de homicídios dolosos ocorridos no estado.

Quanto à estrutura e organização deste artigo, em um primeiro momento serão descritos os aspectos teóricos que envolvem os fatores determinantes do controle da criminalidade e, também, será apresentada a proposta do modelo de mensuração para a questão de pesquisa aqui delimitada. Na sequência serão indicadas as 
variáveis que poderão ser utilizadas para compor o construto teórico. Após isso, nas considerações finais, será destacada a importância prática do trabalho para o sistema de gestão da segurança pública do estado, e, consequentemente, para as ações e políticas de controle dos índices de criminalidade. Pensar nos fatores que dão vida a esses índices é fundamental e justifica a relevância deste estudo, visando contribuir, sobretudo, com a melhoria da segurança pública.

\section{FATORES DETERMINANTES DO CONTROLE DA CRIMINALIDADE}

A princípio é importante dizer que este capítulo do artigo buscará apresentar, de maneira abrangente, aspectos teóricos relativos aos fatores determinantes do controle da criminalidade, embora se considere para a análise do problema de pesquisa proposto os índices de um crime específico: o homicídio doloso. A ciência que se preocupa com o estudo da dinâmica do crime e de suas variáveis é a Criminologia. É preciso pontuar que as diversas correntes do pensamento criminológico acompanharam, no decorrer da história, a evolução das perspectivas teóricas em geral. Interessa, porém, neste trabalho, destacar as principais correntes criminológicas que auxiliam no entendimento dos fatores determinantes do controle da criminalidade. Molina e Gomes (2010) indicam cinco correntes criminológicas básicas, a saber:

a) Criminologia clássica: que tem por base os valores, como, por exemplo, o livre arbítrio, ou seja, a liberdade de escolha. É a corrente que trata o criminoso como um pecador;

b) Criminologia positivista: que se baseia em causas, fatores e determinismos biológicos (elementos contemplados nos estudos desenvolvidos pelo médico psiquiatra italiano Cesare Lombroso) e em determinismos socioambientais, propagados nos estudos da sociologia criminal de Enrico Ferri. Nessa esteira, o crime é considerado como uma patologia intolerável e os criminosos como indivíduos "anormais"; 
c) Criminologia pedagógica ou correcionalista: que considera o criminoso como um coitado, um ser dependente, inferior e incapaz;

d) Criminologia marxista: que relaciona o crime com a exploração existente na estrutura socioeconômica injusta ao explicá-lo a partir das relações de produção e das diferenças de classe. O criminoso é considerado como um produto da injustiça social e, portanto, uma vítima;

e) Criminologia crítica contemporânea: que reconhece o crime como um fenômeno social, intrínseco à convivência social (corrente pautada nos estudos desenvolvidos pelo sociólogo francês Émile Durkheim). Essa diretriz da criminologia não se baseia em determinismos biológicos, socioambientais ou psicológicos, mas se fundamenta em compreender a criminalidade por meio de um viés sócio-político-histórico-cultural. A abordagem da criminologia crítica contemporânea comporta duas teorias: teoria multifatorial e teoria dos elementos condicionantes da criminalidade, que são complementares. Enquanto a primeira entende o crime como um fenômeno sem determinismos e sem exclusivismos, a segunda defende o envolvimento de múltiplos fatores e de elementos condicionantes da criminalidade como: o poder, o desenvolvimento, a desigualdade, a condição humana e o sistema penal.

Cumpre mencionar que a criminologia crítica contemporânea reflete os estudos da teoria funcionalista, que inovou com os estudos clássicos que analisaram o crime sob uma perspectiva patológica e estigmatizada do criminoso. Durkheim (1995), inclusive, reconhece o crime como um fato social normal e necessário, podendo ser cometido por qualquer indivíduo. Na concepção durkheimiana, o crime

Manifesta diretamente uma dessemelhança demasiado violenta entre 0 agente que o executou e o tipo social, ou então ofendem o órgão da consciência comum. Tanto num caso como no outro, a força atingida pelo crime e a que o repele é a mesma; ela é um produto das similitudes sociais mais essenciais e tem por efeito manter a coesão social que resulta dessas similitudes (DURKHEIM, 1995, p. 94). 
O funcionalismo criminológico de Durkheim repele as causas do desvio criminal como consequência de fatores biológicos e patológicos, atribuindo explicação à criminalidade e à estrutura social. Assim, as causas do comportamento desviante estariam no próprio estrato social, o que permite considerar, pelo recorte teórico, que o crime é um fenômeno social, inerente à convivência em sociedade, e, portanto, é multicausal e complexo (AZEVEDO, 2005; ROCHA, 2014). Nesse sentido, Cerqueira e Lobão (2004) entendem que não há como discutir o controle da criminalidade sem que sejam superados os grandes problemas socioeconômicos, em especial aqueles relacionados à desigualdade da renda e ao adensamento populacional, pois, como afirmam os autores, essas questões, por sua vez, "criam um campo fértil para os desajustes sociais".

$\mathrm{Na}$ literatura internacional, Levitt (2004) considera quatro fatores como responsáveis pela redução drástica de crimes nos Estados Unidos na década de 90, são eles: (i) o aumento do número de policiais, (ii) o aumento da população carcerária, (iii) o controle da epidemia do crack e (iv) a legalização do aborto. Em estudo posterior, Blumstein e Rosenfeld (2009) analisaram os fatores que contribuíram para a inversão da tendência de queda dos homicídios e o consequente aumento dos índices criminais nos Estados Unidos a partir do ano 2000 e concluíram que seis aspectos foram determinantes, são eles: (i) a redução das oportunidades de empregos para jovens, (ii) a redução de serviços sociais em decorrência de cortes de financiamento federal, (iii) a redução do número de policiais, (iv) a concentração do trabalho policial em ações relacionadas aos crimes de terrorismo, (v) o controle do crescimento da população carcerária e (vi) a deficiência no trabalho de controle da circulação de armas de fogo.

Os pontos semelhantes entre os estudos desenvolvidos por Levitt (2004) e Blumstein e Rosenfeld (2009) sobre o fenômeno da criminalidade nos Estados Unidos foram: o efetivo policial e a população carcerária. Pode-se inferir, portanto, que o incremento ou a redução do número de policiais empregados na atividade de policiamento são fatores determinantes na dinâmica dos índices de criminalidade assim como o crescimento acelerado ou lento da população encarcerada. Nessa mesma perspectiva, Cerqueira, Lobão e Carvalho (2005) confirmaram a existência de uma 
relação entre a atuação de instituições policiais e de justiça criminal e a ocorrência de homicídios no estado do Rio de Janeiro. Cabe refletir que as estratégias de ações policiais com foco no policiamento de proximidade e na identificação de criminosos contumazes em áreas caracterizadas pela vulnerabilidade criminal influenciam diretamente na segurança pública.

Aliado a isso, verificou-se que em países como Grã-Bretanha, Austrália e Estados Unidos, além do policiamento ostensivo eficiente, a polícia deve promover a prisão dos criminosos, fator que tem influência positiva sobre a redução dos índices de criminalidade (FALLING CRIME, 2013). Assim, após breve discussão teórica sobre os aspectos relacionados ao controle da criminalidade, pautada nos estudos produzidos no país e no exterior, e de acordo com as conclusões de Cerqueira, Lobão e Carvalho (2005), o presente trabalho considera como fatores determinantes do controle da criminalidade: os fatores demográficos, os fatores socioeconômicos, a atividade policial e o sistema de justiça criminal. A partir da problemática evidenciada neste artigo, que se refere aos fatores determinantes do controle da criminalidade no estado do Espírito Santo a partir do ano de 2010 e tomando por base as evidências teóricas criminológicas, foi possível a elaboração da representação gráfica do modelo de pesquisa teórico-hipotético, exposto na Figura 1.

Figura 1 - Modelo de mensuração do construto "controle da criminalidade"

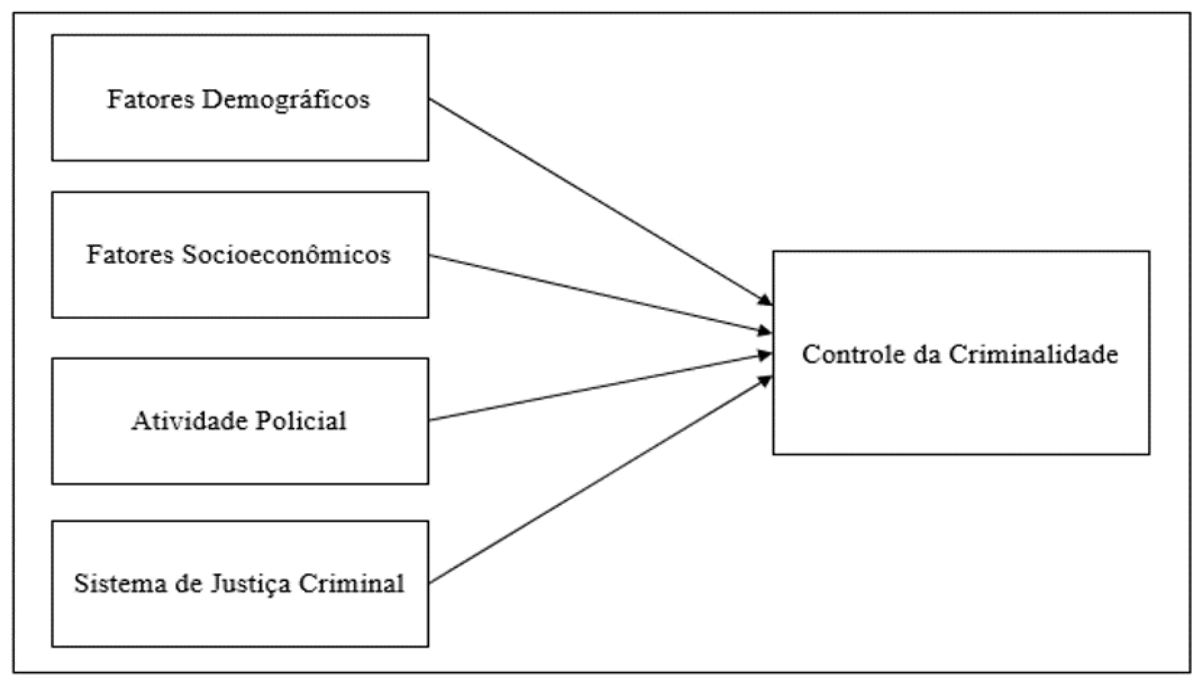

Fonte: Elaboração própria (2020) 
O modelo de mensuração proposto para o construto "controle da criminalidade" compõe-se a partir de quatro dimensões (fatores demográficos, fatores socioeconômicos, a atividade policial e o sistema de justiça criminal), que, conjuntamente, formam os fatores determinantes do controle da criminalidade (homicídios dolosos). O modelo de mensuração, representado na Figura 1, descreve a existência de uma relação entre o construto "controle da criminalidade" e as dimensões descritas. Configura-se como de natureza formativa, isto é, o comportamento das variáveis contidas em cada dimensão determina o comportamento do construto. Em outras palavras, mediante o modelo proposto, o "controle da criminalidade" é determinado pelo comportamento das variáveis que formam as dimensões "fatores demográficos", "fatores socioeconômicos", "atividade policial" e "sistema de justiça criminal".

É de suma importância destacar, ainda, que, neste estudo, não está inserida, na análise, a compreensão das inter-relações entre as dimensões e suas variáveis, mas tão somente dessas com o construto principal. É devido às características do modelo proposto que se pode representá-lo pela regressão múltipla: Controle da Criminalidade $=A \beta 1+B \beta 2+C \beta 3+D \beta 4+$ Erro, de modo que $A$ representa os fatores demográficos, $\mathrm{B}$ os fatores socioeconômicos, $\mathrm{C}$ a atividade policial e $\mathrm{D}$ o sistema de justiça criminal. O próximo capítulo do artigo se dedicará a apresentar as possíveis variáveis que podem ser consideradas em cada dimensão do modelo de mensuração proposto.

\section{MASTER LIST PARA DESENVOLVIMENTO DO MODELO DE MENSURAÇÃO}

Os autores Lewis, Templeton e Byrd (2005) ao escreverem sobre o desenvolvimento de construto em uma pesquisa de Management and Information Systems, propõem três estágios para o percurso metodológico do estudo, a saber: o domínio, a construção de instrumento e a avaliação de propriedades de medição, ambos precisam ser incorporados para que o modelo possa ser colocado em prática. Interessa destacar, neste artigo, o primeiro estágio, no qual, após a definição da 
importância do construto e de sua conceituação, os autores orientam a elaboração de uma master list, isto é, uma lista com todas as variáveis julgadas pertinentes para representar os elementos do construto. Ressalta-se que essa lista pode, quando possível, ser dividida em categorias.

Tendo como referência a questão de pesquisa sugerida para este estudo, além do modelo de pesquisa teórico-hipotético proposto e as diretrizes de Lewis, Templeton e Byrd (2005), formulou-se uma master list para caracterizar as variáveis manifestas das dimensões "fatores demográficos", "fatores socioeconômicos", "atividade policial" e "sistema de justiça criminal", as quais, conjuntamente, determinam o comportamento do construto "controle da criminalidade". Cabe registrar que as variáveis das dimensões "fatores demográficos" e "fatores socioeconômicos" foram organizadas segundo critérios recomendados para os Indicadores e Dados Básicos do Brasil (IDB) do ano de 2012, elaborados pelo Ministério da Saúde do Governo Federal e pela Organização Pan-Americana da Saúde (Opas).

Sobre as variáveis voltadas às dimensões "atividade policial" e "sistema de justiça criminal", é necessário destacar que elas foram organizadas com base nos estudos discutidos na seção teórica do presente trabalho. Vale mencionar que as variáveis manifestas listadas possuem natureza eminentemente quantitativa. É de igual importância mencionar, neste trabalho, que a master list proposta como parte do instrumento metodológico para a representação das variáveis contempladas nas dimensões do modelo de mensuração do construto "controle da criminalidade" está dividida em categorias (dimensões), como se pode ver a seguir:

a) Fatores Demográficos:

1. População total

2. Razão de sexo

3. Taxa de crescimento da população

4. Grau de urbanização

5. Proporção de menores de 5 anos de idade na população

6. Proporção de idosos na população 
7. Índice de envelhecimento

8. Razão de dependência

9. Razão entre nascidos vivos informados e estimados

10. Taxa bruta de natalidade

11. Taxa específica de fecundidade

12. Taxa de fecundidade total

13. Razão entre óbitos informados e estimados

14. Mortalidade proporcional por idade

15. Mortalidade proporcional por idade, em menores de 1 ano de idade

16. Taxa bruta de mortalidade

17. Esperança de vida ao nascer

18. Esperança de vida aos 60 anos de idade

b) Fatores Socioeconômicos:

1. Taxa de analfabetismo

2. Escolaridade da população de 15 anos ou mais

3. Escolaridade da população de 18 a 24 anos

4. Produto interno bruto (PIB) per capita

5. Renda média domiciliar per capita

6. Índice de Gini da renda domiciliar per capita

7. Razão de renda

8. Proporção de pessoas com baixa renda

9. Proporção de crianças em situação domiciliar de baixa renda

10. Taxa de desemprego

11. Taxa de trabalho infantil

12. Proporção de idosos residentes em domicílios na condição de outro parente

c) Atividade Policial:

1. Efetivo da Polícia Civil

2. Efetivo da Polícia Militar

3. Quantitativo de viaturas da Polícia Civil 
4. Quantitativo de viaturas da Polícia Militar

5. Quantitativo de registros de ocorrências da Polícia Civil

6. Quantitativo de registros de ocorrências da Polícia Militar

7. Taxa de homicídios dolosos consumados (1/100.000 hab.)

d) Sistema de Justiça Criminal:

1. Quantitativo de presos no sistema prisional

2. Quantitativo de adolescentes internos no sistema socioeducativo

3. Quantitativo de vagas do sistema prisional

4. Quantitativo de vagas do sistema socioeducativo

Por último, é necessário pontuar que as fontes de coleta dos dados que compõem as variáveis da master list têm acesso facilitado no caso das duas primeiras dimensões, visto que o Ministério da Saúde disponibiliza a coleta mediante plataforma online, de maneira separada por estados, regiões metropolitanas e municípios. Para a obtenção de dados referentes às variáveis da atuação policial e do sistema de justiça criminal, que são as duas outras dimensões, sugere-se a solicitação formal ao Poder Público estadual.

\section{CONSIDERAÇÕES FINAIS}

O problema de pesquisa deste estudo compreende identificar os fatores determinantes do controle da criminalidade no estado do Espírito Santo a partir do ano de 2010, considerando, pra tanto, como parâmetro da criminalidade, os índices de homicídios dolosos. Como demonstrado no conteúdo textual e gráfico deste artigo, o Espírito Santo tem observado, desde o ano de 2010, uma queda considerável nos índices de homicídios, no número bruto dos registros e na taxa de homicídios para cada grupo de 100 mil habitantes. Tal fato tem sido atribuído pela gestão pública estadual às políticas públicas de segurança implementadas pelo Governo estadual (IPEA, 2019; SEGURANÇA PÚBLICA, 2019). No entanto, não há evidências empíricas que indiquem e comprovem os fatores determinantes que influenciaram a redução dos índices dos crimes no território capixaba a partir do ano de 2010. 
A importância da proposta do estudo está em promover o desenvolvimento de uma investigação científica imparcial que se debruce sobre a questão da pesquisa, afastando discursos caracterizados como amadores ou que tenham viés político. A justificativa para o estudo é de cunho teórico e prático. Pressupõe-se que as políticas públicas de segurança combinam aspectos policiais e extrapoliciais com exemplos demográficos e, também, socioeconômicos. A contribuição dos resultados desta pesquisa pode influenciar, inclusive, na manutenção, no aperfeiçoamento ou na exclusão de ações e projetos contemplados nas políticas públicas de segurança, pois com a aplicabilidade do modelo de mensuração proposto será possível identificar quais fatores realmente são determinantes para a redução dos índices de homicídios.

A discussão teórica abordada permitiu elaborar quatro dimensões para o modelo de mensuração, são elas: "fatores demográficos", "fatores socioeconômicos", "atividade policial" e "sistema de justiça criminal". Em conjunto, essas dimensões poderiam demonstrar que influenciam, diretamente, no controle da criminalidade (índices de homicídios). Em ato posterior à identificação das dimensões, apoiando-se nas orientações de Lewis, Templeton e Byrd (2005), elaborou-se uma master list que contém possíveis variáveis manifestas para as dimensões supracitadas. Ressalta-se que há necessidade de amadurecimento da problemática exposta, aprofundamento das bases teóricas, aperfeiçoamento do modelo de mensuração proposto e do seu aspecto metodológico, almejando, portanto, a consolidação da pesquisa e sua posterior aplicação enquanto pesquisa acadêmica empírica.

Deste modo, teve-se como escopo principal, com este artigo, e, também, com a apresentação e discussão dos resultados inerentes à aplicação do método proposto alcançar relevante avanço acadêmico na área de pesquisa que possui como foco as políticas públicas de segurança em nível estadual bem como subsidiar a gestão pública do estado do Espírito Santo e de outros estados do país com a indicação de fatores determinantes do controle da criminalidade, notadamente, dos crimes de homicídios dolosos. Entende-se que os resultados da pesquisa possam ser disseminados e aplicados em contextos estaduais semelhantes ao Espírito Santo em 
se tratando da área da segurança pública, desde que sejam resguardadas as devidas especificidades de cada local.

\section{REFERÊNCIAS}

AZEVEDO, Rodrigo Ghiringhelli de. Criminalidade e justiça penal na América Latina. Sociologias, Porto Alegre, ano 7, n. 13, p. 212-241, 2005.

BLUMSTEIN, Alfred; ROSENFELD, Rosenfeld. Factors contributing to U.S. crime trends. In: GOLDBERGER, Arthur S.; ROSENFELD, Richard. Understanding crime trends. Washington: National Academies Press, 2009, p. 13-44.

BRASIL. Decreto-Lei o 2848, de 07 de dezembro de 1940. Código Penal Brasileiro. Diário Oficial [da] República Federativa do Brasil, Brasília, 07 dez. 1940. Disponível em: http://www.planalto.gov.br/ccivil_03/decreto-lei/del2848compilado.htm. Acesso em: 06/12/2019.

CALIMAN, Orlando. Formação econômica do Espírito Santo: de fragmentos do período colonial à busca de um projeto de desenvolvimento. Revista Interdisciplinar de Gestão Social, Salvador, v. 1, n. 2, p. 37-63, 2012.

CERQUEIRA, Daniel; LOBÃO, Waldir. Criminalidade, ambiente socioeconômico e polícia: desafios para os governos. Revista de Administração Pública, Rio de Janeiro, v. 38, n. 3, p. 371-400, 2004.

CERQUEIRA, Daniel; LOBÃO, Waldir; CARVALHO, Alexandre X. de. O jogo dos sete mitos e a miséria da segurança pública no Brasil. Rio de Janeiro: IPEA, 2005. Disponível em: http://www.ipea.gov.br/portal/index.php?option=com_content\&view=article\&id=4744. Acesso em: 06/12/2019.

DURKHEIM, Émile. Da divisão do trabalho social. Tradução de Eduardo Brandão. São Paulo: Martins Fontes, 1995. 
ESPÍRITO SANTO (Estado). Lei Complementar Estadual no 318, de 17 de janeiro de 2005. Vitória, 2005.2 Disponível em: http://www3.al.es.gov.br/Arquivo/Documents/legislacao/html/lec3182005.html. Acesso em: 06/12/2019.

ESPÍRITO SANTO (Estado). Povo capixaba: origem do termo capixaba. Vitória, 2020. Disponível em: https://www.es.gov.br/historia/povo-capixaba. Acesso em: 02/01/2020.

FALLING CRIME. Where have all the burglars gone? The Economist Newspaper, London, 2013. Disponível em: http://www.economist.com/news/briefing/21582041 rich-world-seeing-less-and-less-crime-even-face-high-unemployment-and-economic. Acesso em: 02/01/2020.

INSTITUTO DE PESQUISA ECONÔMICA APLICADA - IPEA (Brasília). Atlas da violência 2019. Brasília, 2019. Disponível em: http://www.ipea.gov.br/atlasviolencia/download/19/atlas-da-violencia-2019. Acesso em: 29 nov. 2019.

INSTITUTO JONES DOS SANTOS NEVES - IJSN (Espírito Santo). Processo de urbanização, estrutura demográfica e violência: análise no Espírito Santo e Vitória. Vitória, $2011 . \quad$ Disponível em: http://www.ijsn.es.gov.br/component/attachments/download/4802. Acesso em: 29 nov. 2019.

LEVITT, S. D. Understanding why crime fell in the 1990s: four factors that explain the decline and six that do not. Journal of Economic Perspectives, v. 18, n. 1, p. 163190, 2004

LEWIS, B. R.; TEMPLETON, G; BYRD, T. A methodology for construct development in MIS research. European Journal of Information Systems, v. 14, p. 388-400, 2005. 
MINISTÉRIO DA SAÚDE (Brasil). Indicadores e Dados Básicos do Brasil 2012. Brasília, 2012. Disponível em: http:/tabnet.datasus.gov.br/cgi/idb2012/matriz.htm. Acesso em: 01/11/2019.

MINISTÉRIO DA SAÚDE (Brasil). Sistema de Informações sobre Mortalidade do Departamento de Informática do Sistema Único de Saúde (SIM/DATASUS). Brasília, 2019.

Disponível

em: http://www2.datasus.gov.br/DATASUS/index.php?area=060701. Acesso em: 01 nov. 2019.

MOLINA, A. G. P. de; GOMES, L. F. Criminologia: introdução a seus fundamentos teóricos, introdução às bases criminológicas da Lei 9.099/95 - Lei dos Juizados Especiais Criminais. Revista dos Tribunais, 7ª̣. ed. São Paulo, 2010.

MUNIZ, J. de. O; ZACCHI, J. M. Avanços, frustrações e desafios para uma política progressista, democrática e efetiva de segurança pública no Brasil. São Paulo: Fundação Friedrich Ebert Stiftung, 2004.

ROCHA, L. de. M. L. N. Editorial. Revista de Políticas Públicas, v. 18, n. 2, p. 339342, 2014.

SECRETARIA DE ESTADO DA SEGURANÇA PÚBLICA E DEFESA SOCIAL (Espírito Santo). Homicídios dolosos 2019. Vitória, 2019. Disponível em: https://sesp.es.gov.br/estatisticas-criminais-2019. Acesso em: 02 jan. 2020.

SECRETARIA DE ESTADO DA SEGURANÇA PÚBLICA E DEFESA SOCIAL (Espírito Santo). Plano de Segurança Pública e Defesa Social 2019-2022. Vitória, 2020. Disponível em: https://sesp.es.gov.br/plano-da-seguranca-publica. Acesso em: 02 jan. 2020.

SEGURANÇA PÚBLICA Espírito Santo registra queda no número de homicídios. Gazetaonline, Vitória, $2019 . \quad$ Disponível em: https://www.agazeta.com.br/es/gv/espirito-santo-registra-queda-no-numero-dehomicidios-0919. Acesso em: 02 jan. 2020. 
SIQUEIRA, M. da. P. S. A questão regional e a dinâmica econômica do Espírito Santo - 1950/1990. Revista de História e Estudos Culturais, v. 6, ano 6, n. 4, p. 1-16, 2009.

SOARES, L. E. Segurança tem saída. Rio de Janeiro: Sextante, 2006.

\section{APÊNDICE - REFERÊNCIAS DE NOTA DE RODAPÉ}

2. Nos termos da Lei Complementar Estadual no 318, de 17 de janeiro de 2005, a Região Metropolitana da Grande Vitória, também chamada de Grande Vitória, é formada pelos seguintes municípios: Vitória (capital), Vila Velha, Serra, Vila Velha, Cariacica, Viana, Guarapari e Fundão (ESPÍRITO SANTO, 2005).

3. Capixaba é o nome utilizado para se referir a todos os moradores do Espírito Santo (ESPÍRITO SANTO, 2020).

4. De acordo com o Código Penal Brasileiro (Decreto-Lei no 2848, de 07 de dezembro de 1940), o homicídio doloso é a prática de matar alguém, quando o agente quis o resultado ou assumiu o risco de produzi-lo (art. 121, caput) (BRASIL, 1940).

Enviado: Janeiro, 2020.

Aprovado: Março, 2020. 